\title{
UKANYI E GWAZA MUTINE - FESTEJOS CULTURAIS E IDENTITÁRIOS EM MAPUTO E GAZA - MOÇAMBIQUE
}

\author{
UKANYI AND GWAZA MUTINE - CULTURAL AND IDENTITY FESTIVALS IN MAPUTO AND GAZA - MOZAMBIQUE
}

\section{RESUMO}

A Festa de Ukanyi possui uma importância especial ao celebrar o dia dos Heróis de Marracuene e o Ukanyi, no início de fevereiro. Este artigo procura discutir o valor histórico, social e cultural do Ukanyi na construção social das comunidades rurais e como essa bebida e respectiva comemoração, bem como os símbolos a ela associados. se configuram em um bem cultural e identitário de Maputo e Gaza Moçambique. $O$ nacionalismo comparece. Como procedimento recorremos à revisão de publicações, especialmente os relatórios e artigos do Arquivo do Património Artístico e Cultural de Moçambique (ARPAC), e outras nos repositórios científicos nacionais e internacionais. A metodologia baseou-se na análise qualitativa e na observação participativa. Conclui-se que o valor histórico, social e cultural do Ukanyi na construção social das comunidades rurais é inegável, e a presença politica reforça e valoriza a celebração da bebida.

Palavras-chave: Patrimônio; Bem Cultural; Bebida Simbólica; Rituais Festivos; Sul de Moçambique.

\section{ABSTRACT}

The Ukanyi festival is especially important as it celebrates the Heroes day of Marracuene and the day of the Mozambican Heroes, in the beginning of February. This article seeks to discuss the historical, social and cultural value of Ukanyi in the social construction of rural communities, and how this drink and its celebration, as well as the its symbols, are configured in a cultural asset and identity of Maputo and Gaza provinces - Mozambique. As a methodological approach, we reviewed the relevant publications, especially the reports and articles of the Archives of the Artistic and Cultural Heritage of Mozambique (ARPAC), and others in the national and international scientific repositories. We also did a qualitative analysis and participatory observation. We conclude that the historical, social and cultural value of Ukanyi in the social construction of rural communities is undeniable, and this celebration also affects urban populations.

Keywords: heritage; cultural asset; symbolic drink; festive rituals; southern Mozambique

\author{
Maria Geralda de Almeida ${ }^{a}$ \\ D Constâncio A. Machanguana ${ }^{\text {b }}$ \\ ${ }^{a}$ Universidade Federal de Goiás (UFG), \\ Goiânia, GO, Brasil

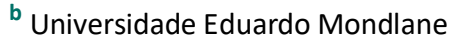 \\ (UEM), Maputo, Moçambique
}

DOI: 10.12957/geouerj.2020.53911

Correpondência: gdealmeida@ufg.br

Recebido em: 24 jun. 2019

Revisado em: 11 jan 2020

Aceito em: 15 mai 2020 


\section{CHEGANDO AOS FESTEJOS}

A Festa do Ukanyi, tradição no sul de Moçambique, acontece em finais de janeiro e princípios de fevereiro. Duas datas marcam essa festa, em Maputo: o dia 2 de fevereiro - dia dos Heróis de Marracuene (Gwaza Mutine) - e o dia 3 de fevereiro - feriado nacional, dia dos Heróis. Tradicionalmente, do dia 3 até ao fim de fevereiro, só se bebe Ukanyi em Maputo e Gaza. O dia dos Heróis e o feriado nacional associam-se, pois, com a celebração do Ukanyi, de intenso significado simbólico e cultural para os moçambicanos do sul do país.

De acordo com Almeida (2012), etimologicamente, festa dhies é um dia de celebração marcado por um contexto religioso. Em latim, le dies festus é o dia "tocado" de um signo especial, como a bebida Ukanyi, que comemora seus heróis. É o dia da demonstração pública pela qual se deseja "tocar" o espírito do próximo, atrair fortemente sua atenção, mostrar evidência, fazer a celebração triunfar, manifestá-la, associando o Ukanyi com os mortos celebrados.

Este artigo procura discutir o valor histórico, social e cultural do Ukanyi na construção social das comunidades rurais e como essa bebida e respectiva comemoração, bem como os símbolos a ela associados, se configuram em um bem cultural e identitário de Gaza - Moçambique.

Para fazer esta discussão, recorremos à revisão de publicações, especialmente os relatórios e artigos do Arquivo do Património Artístico e Cultural de Moçambique (ARPAC), e outras em repositórios científicos nacionais e internacionais. Foram priorizadas a análise qualitativa e a observação participativa. Conduzimos entrevistas não estruturadas com os principais sujeitos na organização e coordenação das festas do Ukanyi, em Maputo e Gaza, designadamente líderes comunitários e produtores dessa bebida.

Pretende-se com este debate destacar um bem cultural moçambicano, as memórias, o patrimônio e os conhecimentos locais sobre os valores do Ukanyi e sua celebração, convenientemente realizada no mesmo dia da festa do Heróis, um feriado nacional.

Primeiramente, será discutido como o Ukanyi é um modo de mobilizar a sociedade, fortalecer tradições e reviver a história de parte de Moçambique. Ou seja, o sentido e significado desse bem cultural. Prosseguiremos apresentando a origem, isto é, a planta que produz os frutos e a preparação do ritual; posteriormente, o significado dessa festa associada à comemoração do dia dos Heróis como estratégia para reforçar a identidade moçambicana. 


\section{UKANYI: SIGNIFICADOS E RITUAIS}

De acordo com Fabre (1994), apesar de nossas sociedades se definirem como modernas, ou seja, engajadas em um processo contínuo de transformação histórica, elas são também sociedades de conservação, de valorização do passado. Se associarmos essa concepção com o Ukanyi e sua celebração, veremos que eles não possuem uma origem na história moçambicana. Contudo, eles constituem um bem cultural, conforme explicaremos neste texto.

Nos tempos idos, a frutificação, a fabricação e o posterior consumo de Ukanyi marcavam a transição do ano no seio das comunidades. Uma outra importância associada ao Ukanyi que prevalece atualmente está relacionada, por um lado, com o fortalecimento das relações sociais e, por outro, com a criação de novos laços de solidariedade. É durante a época de Ukanyi que se registram com maior frequência visitas entre indivíduos pertencentes a uma mesma família, incluindo membros de diferentes comunidades. As pessoas agrupam-se, aproximam-se para conviver e discutir vários assuntos ligados à sua vida e àquela da sua comunidade. É também uma ocasião propícia para novas relações e amizades.

Fora da época de Ukanyi, Maputo desempenha sua função político-administrativa em relação a Moçambique, e Marracuane, na região metropolitana da capital, é, principalmente, uma vila-dormitório. Elas são lugares em que o tempo e as relações sociais são de fraca intensidade, remetendo à caracterização de lugares estáveis feita por Certeau (2006). Contudo, no período de janeiro a março, quando decorre o ritual de Ukanyi, esses locais se transformam quase que radicalmente, reconfigurando-se, pelo intenso fluxo e pelas festividades, em instáveis, como salienta o mesmo autor.

Como já o dissemos, esse é o momento em que os indivíduos procuram se reunir e celebrar o ritual de Ukanyi. Com isso, aumenta a interação entre eles, tornando as relações sociais mais intensas e ampliando a tensão e a dinâmica daqueles espaços, sobretudo com a aproximação do urbano local da reunião e dos festejos com o rural, local da árvore do canhoeiro, cientificamente conhecido como Sclerocarya birrea, produtora do Ukanyi.

O canhoeiro ocorre em alguns países do continente africano, tais como: Moçambique, África do Sul, Namíbia, Suazilândia, Zimbabwe, Botsuana, na África Equatorial, entre a Etiópia e o Sudão, a norte, Angola e Uganda. Essa árvore está também presente no Madagáscar, nas Maurícias e Ilhas Reunião. E também foi testado seu plantio em Israel, na Austrália e na Índia (DPP, 2010). Essa ocorrência extensa não tem o registro de bebida e festejos de igual valorização cultural, razão pela qual ressaltamos a celebração existente no sul de Moçambique. Sem dúvida, uma celebração que agrega a natureza e o social, contemporaneamente, reafirmando a importância atribuída ao Kanhyu. Pode-se afirmar que, desde a colheita do fruto da árvore, ocorre a nutrição das tradições locais, conforme figura 1. 
Figura 1. Fruto do canhoeiro com as sementes com as quais se prepara o Ukanyi. Fonte: http://1.bp.blogspot.com/c5I4rvr3q5o/UuoxnFtTeGI/AAAAAAAABtA/HBKBHpJnlt4/s1600/ucanhi+1.gif, (2019).

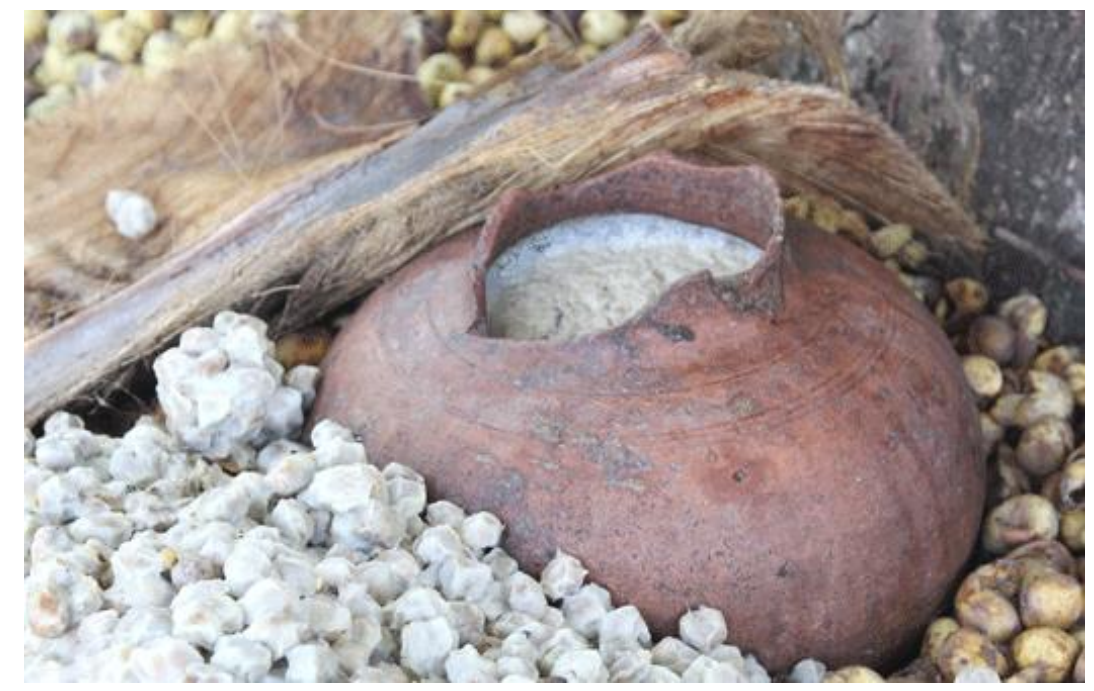

Essa celebração movimenta quase toda uma estrutura de vida social, dinamizando e refazendo os sujeitos, envolvendo as dimensões sociocultural, política e econômica (Machanguana \& Almeida, 2018). Ela mostra sua capacidade mobilizadora da rotina das pessoas, mas também a dos lugares onde o ritual acontece, transformando-os continuamente.

O ritual de Ukanyi cria e fortifica as redes de solidariedade entre habitantes de diferentes biomas. Esse fato, por sua vez, se revela importante na resposta às crises provocadas por calamidades naturais, como as cheias, secas ou inundações, no âmbito da segurança alimentar ou da ruptura de reservas de sementes para a agricultura.

No que se refere à dimensão espiritual, o Ukanyi reveste-se de uma importância essencial na manutenção do equilíbrio social. A época de Ukanyi é vista como a fase de maior aproximação das populações locais aos espíritos dos seus antepassados. O encontro com os espíritos se faz pelas preces de várias ordens, tendo como finalidade a busca de um equilíbrio cosmológico. Machanguana \& Almeida (2018) ressaltam que há, assim, um momento de adoração e evocação do poder dos espíritos dos antepassados para abençoarem a comunidade no ano que se segue. Pela sua dimensão espiritual, criou-se a sacralização da bebida, transformando-a num produto cuja venda é proibida, o que não impede que seja feita sorrateiramente.

Para as comunidades do sul de Moçambique nas províncias citadas, a fabricação de Ukanyi tornou-se uma das atividades que acompanham alguns momentos das suas vidas e revela uma identidade cultural. Com efeito, o Ukanyi é indispensável nos eventos socioculturais, quer no seio da família, quer no das comunidades, pelo menos durante os primeiros meses do ano. É um patrimônio. E, como já foi ressaltado em outros estudos, 
o patrimônio constitui-se como uma nova base de reafirmar a identidade, e a patrimonialização é um recurso para a conservação de símbolos e signos culturais (Almeida, 2012).

Os moçambicanos zelosos do significado e do valor do Ukanyi o tornaram uma importante atração na festa da Marrabenta, já tradicional no calendário moçambicano. A bebida é preparada na véspera das festividades para que esteja disponível naquela data em quantidades suficientes para todos.

Nas províncias do sul de Moçambique, a festa do Ukanyi é celebrada entre os meses de janeiro a março, época em que se efetuam as colheitas nos campos agrícolas. Essa época é tradicionalmente chamada na língua tsonga como "nguva ya Ukanyi", que significa época do Ukanyi. Esse é, também, o período em que se realiza uma variedade de rituais afins ao Ukanyi, provocando uma efervescência coletiva, caracterizada por uma série de rituais (Cossa, 2017, p. 250).

Trata-se de uma época em que se registra o pico do verão, acompanhado de fortes chuvas e umidade. É, ainda, o período das férias escolares, mas também das férias dos trabalhadores moçambicanos nas minas da África do Sul. Moçambicanos que possuem familiares naquele país acolhem seus magaizas, termo local para visitantes. A presença dos maridos e filhos em casa, depois de longos meses nas minas, confere motivos para festejos.

Além disso, o culto aos antepassados para abençoarem o ano recém-iniciado acompanha os festejos do Ukanyi, tanto que uma das bebidas usadas nos rituais de consagração e adoração aos deuses é o próprio Ukanyi.

Além disso, o culto aos antepassados para abençoarem o ano recém iniciado, acompanha os festejos do Ukanyi, tanto que uma das bebidas usadas nos rituais de consagração e adoração aos deuses é o próprio Ukanyi.

Segundo relatos populares dos anciãos e fazedores da bebida, o ritual de Ukanyi comporta três momentos sequenciados, designadamente: kuhawula mindzheko ${ }^{1}$; xikuwha ${ }^{2}$; e kuhayeka mindzheko ${ }^{3}$, sem as quais o sucesso da época de Ukanyi fica comprometido.

O período de produção do Ukanyi é carregado de significados sagrados e altera, por algum tempo as dinâmicas de organização e relações sociais comunitárias. Valoi (2010) explica que durante esta época, a atividade agrícola é temporariamente suspensa e as lideranças comunitárias se aproximam da população para orientarem os rituais de consagração e adoração aos espíritos dos antepassados nas diversas festividades que

\footnotetext{
1 Tirar de algum lugar onde estavam guardados os utensílios usados na preparação e consumo da bebida.

2 Um pote usado para a fermentação da bebida. Simboliza o ponto mais alto das comemorações da época.

3 "Guardar os utensílios" - Significa o fecho da época festiva do Ukanyi.
} 
acontecem na comunidade. Há também, muitas ocasiões e lugares previstos no calendário festivo na região de Maputo, nos quais a bebida é apresentada à comunidade para consumo.

Algumas pessoas na comunidade comentam que a maior parte das famílias que têm o canhoeiro preparam a bebida, e vizinhos e amigos são convidados para beberem. As famílias que não tenham em seu quintal ou machamba esta árvore, ajudam as possuidoras a apanharem o fruto do Ukanyi e a fermentar a bebida. Os líderes comunitários e guardiões dos costumes ficam atentos ao processo e zelam para que o aspecto sagrado da bebida seja observado, como por exemplo, a proibição da comercialização (Machanguana \& Almeida, 2018).

\section{O RITUAL SAGRADO DO UKANYI}

O ritual de Ukanyi segue três principais fases, documentadas e sistematizadas em seus significados por Cossa (2017) e Dava (2009).

Ele começa com a fase denominada de kuhawula mindzheko, o momento em que se anuncia a abertura oficial da época de Ukanyi, e a partir desse ato fica liberado o consumo. Segundo os entrevistados, o consumo da bebida é proibido antes da realização de um ato de devoção aos deuses pelos chefes tradicionais. Estes devem oferecer o primeiro gole aos defuntos, derramando um bocado do líquido no chão, um sinal de agradecimento pelas bênçãos e pelas colheitas da época. Nesse ato, é simbolicamente inaugurado o $n d z h e k o$, este uma espécie de copo feito à base da casca de um fruto silvestre, usado para tomar as bebidas fermentadas, como o Ukanyi (figura 2).

Kuhawula mindzheko é, simbolicamente, quando se anuncia aos ancestrais a chegada da época de Ukanyi e que se roga a eles para o sucesso do ano que segue, dos trabalhos na machamba e proteção para os maridos e filhos que irão trabalhar fora do país nas minas.

Há penalizações para quem ousar servir o Ukanyi antes da inauguração oficial, tal qual podemos observar:

estas proibições levam a pensar num conjunto de normas que condicionam a realização do ritual e orientam a conduta dos indivíduos e consequentemente nos remetem a questões jurídicas, ou seja, ao que chamaríamos de direito intercultural, aqui relacionado ao conjunto de normas tradicionalmente instituídas ou institucionalizadas que regem um grupo ou grupos de indivíduos (COSSA, 2017, p. 251).

Da observação feita a essa festividade, pode-se constatar que, depois da abertura, é comum ver em muitas famílias grupos de pessoas reunidas em volta dos potes ou galões de Ukanyi. Isso é, muitas vezes, acompanhado de cânticos ou músicas que incitam à dança. 
A segunda fase dessa festividade é a celebração do consumo do Ukanyi, também chamada xikuhwa. Esta fase é o auge do ritual de Ukanyi, sendo a festa tradicional popular de Ukanyi que "simboliza o encontro entre os membros de uma comunidade ou de várias comunidades" (Cossa, 2017, p. 251). Esse autor explica que não se trata apenas de uma reunião entre as pessoas, mas de um encontro destas com os ancestrais por via de alguns rituais, como o kuphahla ${ }^{4}$, tida como uma prática presente em todos os rituais de Ukanyi e em todas as etapas do ciclo da época de Ukanyi.

A terceira e última fase é o encerramento das festividades. Conhecida como kuhayeka mindzheko ${ }^{5}$, esta é a etapa na qual se anuncia o fim do Ukanyi e em que se presta agradecimento aos ancestrais pelo sucesso da época ou se faz a exposição dos dissabores ocorridos, pedindo para que não se repitam em situações vindouras (Cossa, 2017).

\section{UKANYI: DA ÁRVORE AO PREPARO DA BEBIDA}

O canhoeiro, repetimos, possui uma grande importância para as comunidades no sul de Moçambique, principalmente em Maputo e Gaza. Em algumas regiões, reveste-se de valores associados à sacralidade, noutras a aspectos políticos e, especialmente, utilitários. Essas qualidades, por um lado, tornam a árvore mítica e especial, no contexto da proteção cultural, e, por outro lado, a inserem na vivência política e cotidiana das comunidades.

A árvore é uma dicoteledônea da família Anacardiadeae, uma árvore de porte médio que pode atingir de 10 a 15 metros de altura. Seus frutos são ovoides ou globosos com uma polpa suculenta, doce-acidulada, e uma semente. A produção anual de Ukanyi por árvore é de cerca de sete mil frutos, que correspondem a uma média de 500 kg árvore/ano.

O núcleo da semente é rico em proteína e gordura, com um sabor de nozes, constituindo uma boa fonte de alimentação. As frutas são comumente comidas frescas ou preparadas em sucos, geleias e licores - sendo entre estes o mais conhecido o da marca Amarula, produzido pela fermentação de seu suco; o óleo de Ukanyi, feito a partir do núcleo da semente, é usado na África como protetor antioxidante da pele; a casca da árvore pode ser usada no tratamento e na profilaxia da malária; o chá das folhas do canhoeiro é recomendado no tratamento da indigestão; a fruta é uma importante fonte alimentar para diversos animais, porém pode provocar embriaguez naqueles que a comem em excesso, devido ao álcool que é gerado no processo de fermentação.

\footnotetext{
${ }^{4}$ Nome em língua local (xi changana) atribuído ao ritual de invocação dos ancestrais.

${ }^{5}$ Que significa pendurar os utensílios usados para fermentar e beber o Ukanyi.
} 
Segundo o manual de produção do Ukanyi (DPP, 2010, p. 1), a povoação do canhoeiro pela região austral de África deu-se graças à migração do povo bantu, para os quais a fruta dessa árvore era importante na sua dieta desde os primórdios.

No concernente às questões políticas, o canhoeiro está associado a aspectos como a lealdade às tradições e o respeito aos símbolos comunitários. É nesse contexto que se estabelece a relação entre o canhoeiro e os aspectos políticos, pois, no seio das comunidades, essa árvore simboliza o poder do chefe tradicional. O canhoeiro é das árvores que em momentos importantes os líderes comunitários e seus súditos se sentam à sua sombra, discutem e resolvem os vários problemas que afetam a comunidade.

De acordo com Valoi (2010), durante o período de festa popular, o líder comunitário fica mais próximo da população sob a sua jurisdição, e são organizadas campanhas de apanha de makanyi (plural de akanyi fruto de n'kanyi/canhoeiro - árvore) para a preparação da bebida na casa do líder local. Diferentemente de muitas outras bebidas, para o Ukanyi as famílias não têm nenhum ônus financeiro para a preparação dessa bebida. Segundo depoimentos populares, a preparação do Ukanyi é um ato prestigioso e uma valorização dos saberes locais. O fruto do canhoeiro é apanhado quando cai da árvore,conforme já relatamos, muitos membros da família se envolvem nessa atividade, especialmente as mulheres e crianças.

Durante o período da recolha do fruto do canhoeiro, as leis sociais normais são mais ou menos suspensas, incluindo a atividade agrícola, de forma a liberar as famílias para que possam participar do grande momento da festa comunitária.

Para esse processo, as comunidades organizam-se da seguinte forma: por um lado, as mulheres encarregam-se de recolher makanyi, os frutos, e juntá-los num único lugar, geralmente amontoados ao pé da árvore até a maturação. Esta pode levar entre 3 a 5 dias. Depois desse tempo, as mulheres furam cada kanyi e lançam no tambor/bacia para que possa derramar o líquido. Nessa primeira fase, a casca e o caroço são lançados na bacia para fermentar. Não há muitos cuidados com a limpeza prévia do makanyi antes de ser furado e jogado na bacia/tambor.

Por outro lado, os homens se ocupam da preparação dos locais comunitários onde se irá reunir a comunidade para as celebrações e o consumo da bebida. Eles limpam a área e montam os bancos com material local, erguem as sobras de árvores e galhos ou podam as árvores de sombra existentes no local para acomodar as pessoas que se vão reunir. À noite, é acesa uma fogueira à volta da qual as pessoas se reúnem. A fogueira serve para iluminar o local e para assar carne e maçaroca/milho.

Cossa (2017) classifica a etapa da preparação do ritual de Ukanyi como um dos momentos em que homens e mulheres por meio das conversas compartilham conhecimentos, suas vivências e as experiências do 
seu dia a dia. E, além do mais, é um período no qual homens e mulheres encontram-se mais próximos uns dos outros, unidos pela mesma celebração.

No local do ritual, é comum observar que os homens sentam-se de um lado e as mulheres de outro, embora estejam juntos. O Ukanyi é colocado em potes de barro denominados khuwane, e ao lado dos potes vão os alguidares de barro, chamados lihisu, em que são conservadas as cabaças ndzeko, que, já o dissemos, são usadas para servir e beber Ukanyi, conforme figura 2, a seguir.

Figura 2. Moçambicano bebe Ukanyi no ndzeko. Marracuene. Autora: Almeida, M. G. de (2017).

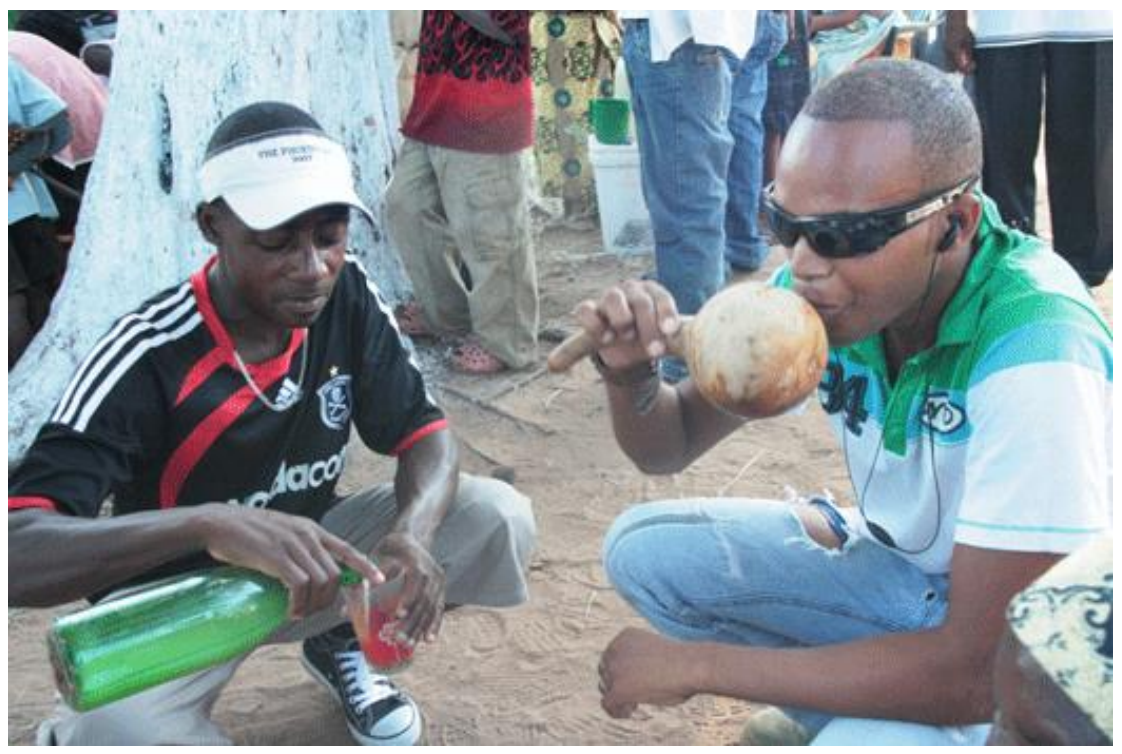

No final do ritual os alguidares são usados para conservar o hongwe ${ }^{6}$, o qual constitui a bebida que fica no fundo do pote, misticamente afrodisíaca. Essa porção da bebida é aconselhada somente aos casados, particularmente homens, dado ao seu poder de fortalecer a potência sexual. O Ukanyi é, muitas vezes, associado às situações de adultério, por estimular o desejo sexual tanto nos homens quanto nas mulheres.

A música, as danças tradicionais são os principais condimentos que acompanham as sessões de consumo da bebida, que se podem estender noite adentro. Roupas e acessórios típicos locais são preparados e usados a rigor, reforçando uma identidade local. Uma identidade cultural, como já evidenciado, que possui componentes que formam um todo integrado, inter-relacionado e único como a língua, a história, o território, os símbolos, as leis, os valores e as crenças, e os elementos tangíveis, na concepção de Almeida (2012). O Ukanyi é, dessa maneira, a estratégia para, anualmente, relembrar e reforçar essa identidade.

\footnotetext{
${ }^{6}$ Nome em xi changana designa a parte mais densa de Ukanyi, na qual se acredita residir a maior concentração do teor afrodisíaco dessa bebida tradicional.
} 


\section{CELEBRANDO HERÓIS E FORTALECENDO A IDENTIDADE}

A época de Ukanyi é um marco importante, especialmente em Maputo e Gaza. Em Maputo, particularmente, a festa é celebrada acompanhada das comemorações dos aniversários das batalhas das lutas contra a ocupação colonial portuguesa.

Em Moçambique, momentos históricos são pouco festejados. Porém, o Combate de Marracuene, ou Gwaza Muthine, que se travou a 2 de fevereiro de 1895, em Marracuene, na margem direita do rio Incomati, tem um significado especial para os moçambicanos. Esse combate aconteceu entre a expedição portuguesa, constituída de 37 oficiais e 800 soldados, e as forças ronga, resistência local da tribo ronga, totalizando cerca de 4.000 homens comandados pelo jovem príncipe ronga nwa Matidjuana e outros generais locais, Zixaxa e Mpfumo. No final, a superioridade das armas de fogo ocidentais foram cruciais para a vitória da tropa portuguesa. No terreno, ficaram mortos cerca de 66 guerreiros rongas.

Até 1974, realizava-se a comemoração da vitória dos portugueses, mas, depois da Independência Nacional, em 1975, homenageiam-se os heróis moçambicanos tombados no confronto. Durante todo o tempo Colonial, os heróis eram os portugueses mortos na batalha, e os moçambicanos diziam 'bayetee', que significa render homenagem. As comemorações de Gwaza Muthini foram reativadas no dia 2 de fevereiro, em 1994, e Gwaza passaria a ser o símbolo da heroicidade contra a ocupação portuguesa no sul de Moçambique (figura 3):

Figura 3. Representação da comemoração 122 da batalha de Marracune. Fonte: https://ivairs.wordpress.com/category/historia/page/6/ (2017).

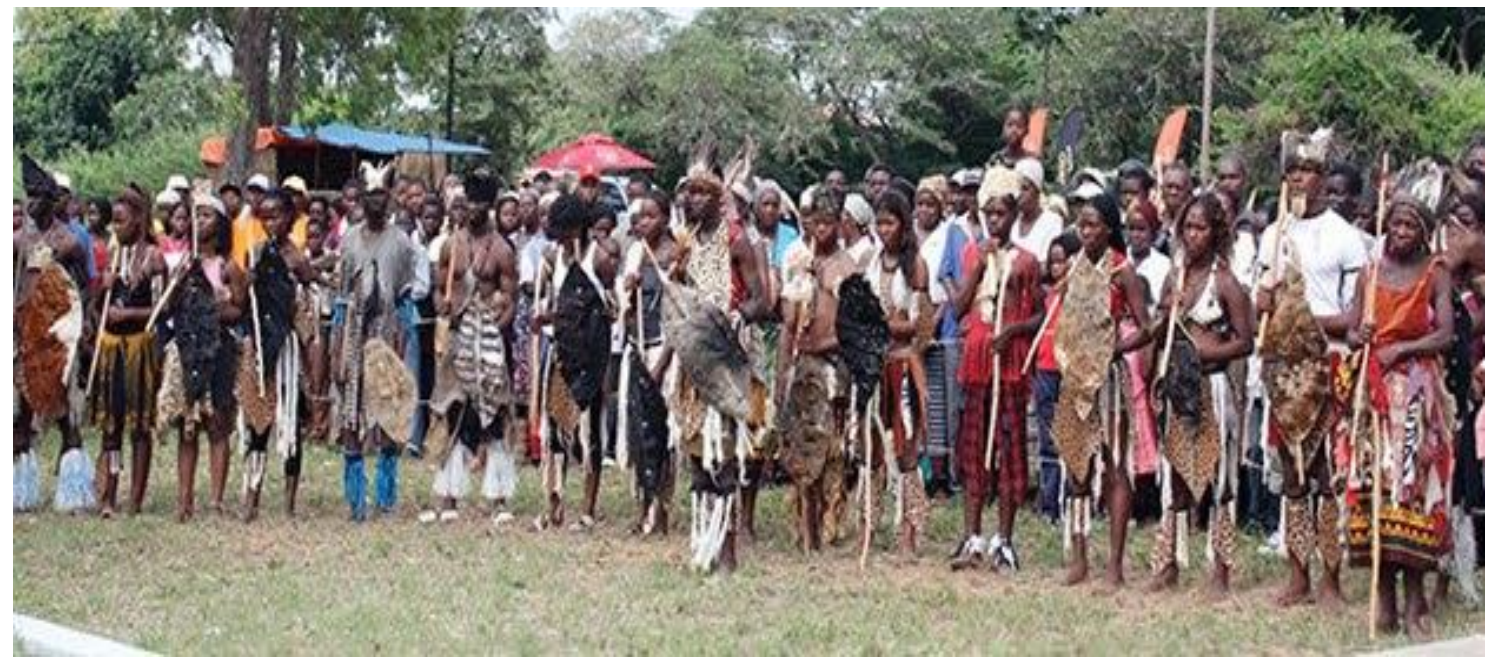

Após as cerimônias habituais de 'Kuphahla', isto é, a evocação dos espíritos dos antepassados, da deposição de flores junto ao monumento que lembra os guerreiros tombados em Marracuene, da entoação 
do Hino Nacional e dos discursos de praxe, têm início as atividades culturais. Convém ressaltar que essas cerimônias são, predominantemente, políticas. O Governador, os representantes de presidência e militares comparecem à cerimônia e têm destaque na presidência da cerimônia em um palanque ornamentado para acolhê-los (figura 4). As lideranças comunitárias, os anciãos e régulos convidados comparecem com trajes típicos e conduzem as cerimônias tradicionais. Eles têm prestígio e assentos ao lado do palanque político. Na festividade, seus cânticos intercalam alguns discursos.

Figura 4. Autoridades nas comemorações de Gwaza Muthini. Marracuene. Fonte: M. I. Almeida (2017).

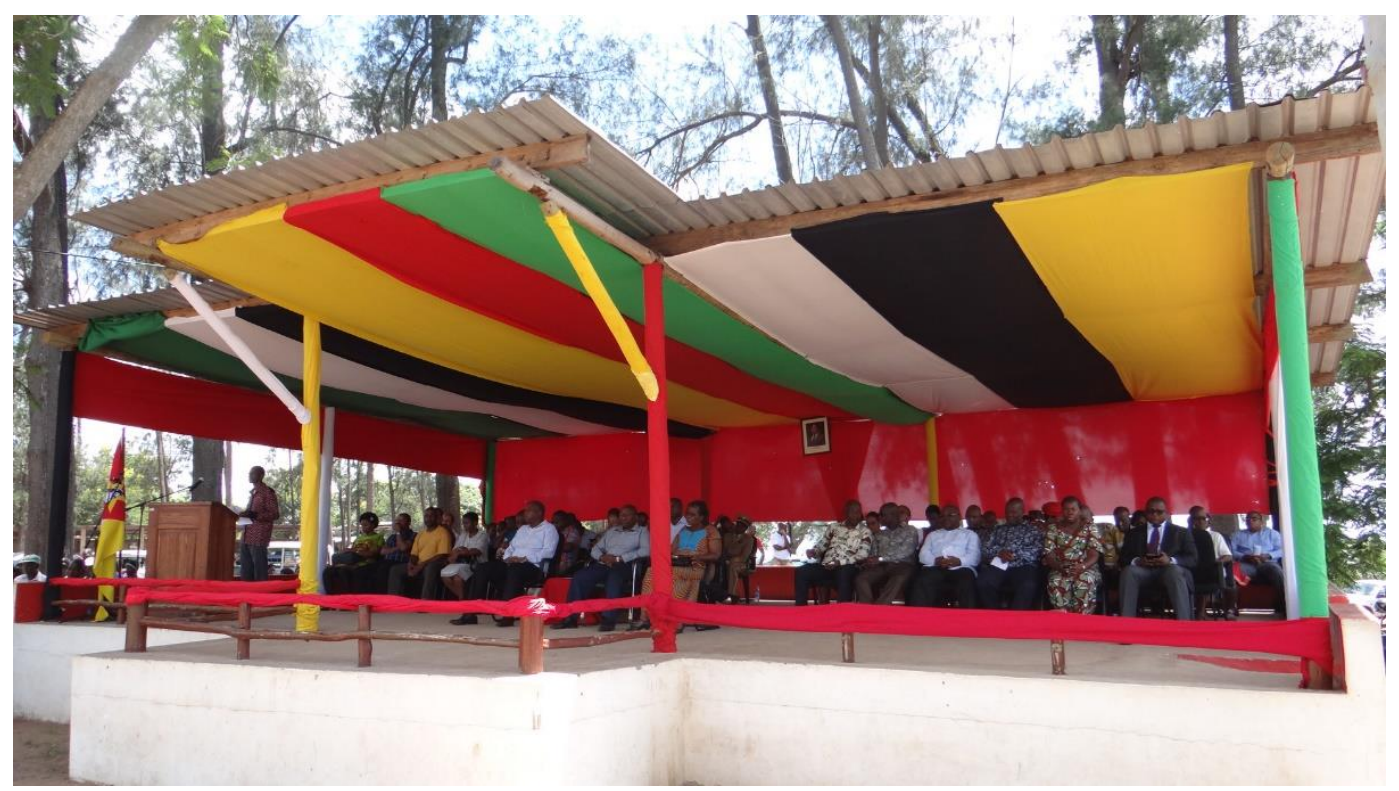

É interessante notar que essa época acontece no período de verão, coincidindo com as férias, o que induz à reflexão sobre essa festa constituir um possível atrativo turístico tanto para os nacionais quanto para os estrangeiros, que a essa altura buscam o sul de Moçambique à procura de praias.

Tanto as festas quanto o turismo em suas práticas são efêmeros, porém marcam significativamente seus territórios. Essa aproximação do turismo com as festas rurais é um pretexto para entender como o Ukanyi, o patrimônio cultural, poderá se constituir em forte atrativo para a turistificação. Políticos e empreendedores certamente defenderão ardorosamente o turismo, considerando-o criador e impulsionador de novas atividades econômicas nas localidades principais nas quais ocorrerem as celebrações.

O Ukanyi tem um sentido e valor local. Contudo, para o visitante, essas celebrações são exóticas, embora simultaneamente e para os moçambicanos, elas tenham uma carga mítica, sagrada e, paralelamente, de valor patriótico e nacionalista. As celebrações se tornam atrativas por outro significado, e o bem cultural ganha outro sentido para os visitantes estrangeiros. 
Cabe ressaltar que o patrimônio tem sido usado e abusado como aliado da prática do turismo. Os bens que integram esse patrimônio são utilizados como recursos que constituem ou complementam a oferta de serviços e que atraem e disponibilizam novas ofertas de caráter cultural, lúdico e recreativo à população. Assim, muitos elementos patrimoniais se utilizam como marcas identitárias de um lugar, como instrumentos de marketing orientados a dar a conhecer e atrair recursos exteriores.

As manifestações culturais, os hábitos e costumes, a gastronomia e as línguas nas regiões de Maputo e Gaza são intimamente relacionados e similares, diferentemente das outras regiões do país. A estrada que vai de Maputo a Macia e para Xai-xai e Chóckwe e Chilembene, e ou passando de Manjacaze e Chibuto, na província de Gaza, permanece desconhecida para a maioria dos jovens nascidos depois de 1990. Em vários locais dessas localidades, existem monumentos que revelam parte da história dos povos shona constituintes do império de Gaza, que se estendia até Zimbabwe.

Esses locais possuem vários marcos históricos dos antepassados, os heróis da resistência contra a ocupação estrangeira, como é o monumento a Ngungunhana, último imperador de Gaza, em Chibuto; a casa de Samora Machel, em Chilembene; a Casa de Eduardo Mondlane, primeiro presidente de Moçambique após a independência, em 1962, em Manjacaze; e o monumento aos heróis de Marracuene, já na capital, Maputo. Conhecer esses traços da história nacional pelos jovens e estudantes é importante para se entender algumas celebrações do Ukanyi. Além disso, urge que os políticos e decisores repensem o modelo de turismo doméstico e considerem a necessária inclusão do conhecimento valorativo dos heróis nacionais.

Ao incluir os festejos do Ukanyi em uma proposta turística destinada aos estudantes e aos turistas ocasionais, estes poderão presenciar que os moçambicanos participantes da celebração procuram resgatar os cânticos folclóricos e dançar as coreografias antigas, além das canções relembrando as guerras de resistência contra a ocupação colonial. Será a oportunidade de um encontro com um patrimonio cultural que reside, ainda, na memória de poucos.

\section{DESPEDINDO-SE DAS FESTAS}

A época de Ukanyi é o período em que a sociedade, fortemente concentrada, encontra-se num estado crônico de efervescência e superatividade. Nesse período, os indivíduos estão mais intimamente próximos uns dos outros, as ações e reações sociais são mais numerosas, mais frequentes, mais contínuas, trocam-se ideias, os sentimentos entre os indivíduos intensificam-se e se reforçam mutuamente. Os grupos moçambicanos, intensamente ativos, têm reforçado o sentimento de si mesmos e de sua identidade cultural. Dessa maneira, reforça e consolida a identidade moçambicana na consciência dos indivíduos. Repetimos, no sul de Moçambique, a festividade de Ukanyi constitui um forte elemento de coesão social e político, sabidamente aproveitado pelos governantes, conforme o exposto. 
A festividade e o consumo do Ukanyi são essenciais, embora em transformação, na construção social da sociedade moçambicana. Eles são notórios na continuação da sua valorização, especialmente nas comunidades rurais. Embora o fruto do canhoeiro seja a base para a fabricação de uma das bebidas mais famosas "made in south África", a Amarula, , seu valor não é econômico no sul do Moçambique, onde se ressignificam a tradição e os valores culturais.

A valorização e imortalização das festividades locais dos povos e das bebidas tradicionais e a passagem de testemunho para as novas gerações são um contributo para que a história dos povos se perpetue e seja finalmente catalogada como bem cultural.

E, para e pelo turismo, esse bem cultural pode ser inventado como turístico e criados centros de peregrinagens, festas e tradições folclóricas, festivais gastronômicos, monumentos artísticos e simbólicos, lugares de romarias e de celebrações como atrativos turísticos. Essa atividade pode promover o desenvolvimento local caso bem planejada e articulada com a participação dos partícipes do Ukanyi e da Festa dos Heróis.

Neste artigo, procurou-se apresentar as festividades aliadas ao consumo do ukanyi como patrimônio histórico e cultural de um povo. O Ukanyi faz parte do ser moçambicano, e sua permanência como tal depende de ser destacado, documentado e sistematicamente visitado pelas gerações mais novas. O valor histórico, social e cultural do Ukanyi na construção social das comunidades rurais é inegável, cuja celebração atinge também as populações urbanas. O Ukanyi somente é festa porque envolve o coletivo, a solidariedade, a alegria. E constitui uma forte expressão identitária valorizada.

\section{REFERÊNCIAS}

ALMEIDA, M.G. Sentidos das festas nos lugares e patrimonio turísticos.. In: COSTA, E..B.; BRUSADIM, L.B.; PIRES, M.C. (Orgs.). Valor patrimonial e turismo: limiar entre história, território e poder. São Paulo-SP: Outras Expressões, 2012.

BILA, J. M., C., I., \& CARVALHO, N. Nota Científica Potencialidades de Sclerocarya birrea em Chigubo província de Gaza, Moçambique. Brazilian Journal of Forestry Research, vol. 37, n. 90, 2017, p. 213-217. Disponível em:

<https://doi.org/10.4336/2017.pfb.37.90.1059> Acesso em: 29 dezembro 2018.

CERTEAU, M. "Relatos de espaço". In: A invenção do cotidiano. Artes de fazer 1. Petrópolis: Editora Vozes, 2011.

COSSA, D.M. O Ritual de Ukanhy: uma tradição na modernidade. Monografia (Licenciatura em Sociologia) - Faculdade de Letras e Ciências Sociais, Universidade Eduardo Mondlane, Maputo, 2013.

COSSA, D. M. A. Um olhar da antropologia das paisagens e espaços sobre o ritual de ukanyi. Revista Intratextos, vol. 8, 2017,

DAVA, F. Ritual das Primícias de Ukanyi. Maputo: ARPAC, (Vol. 29), 2009.

DPP. Marula: Production guideline. Pretoria: Department of Agriculture, Forestry and Fisheries, 2010.

FABRE, D. Ethenologie et Patrimoine en Europe. Terrain. n. 22. Les émotions, 1994.

HARTOG, F. Tempo e patrimônio. Varia História, Belo Horizonte, v.22, n.36, jul/dez. 2006.

MACHANGUANA, C. A., \& ALMEIDA, M. G. Ukanyi, Festejos, patrimônio e celebrações em Maputo e Gaza - Moçambique: proposta para um roteiro turístico rural. In AULP (Ed.), XXVIII Encontro da AULP, Lubango, 18-20 Julho Lisboa: AULP, 2018.

VALOI, A. Ukanhy Festival: N'kuvu wa wukanhy. 2010. Disponível em: <http://www.dekhanaproducoes.com/news/ucanhy\%20festival\%20\%20n\%C2\%B4kuvu\%20wa\%20wukanhy/> Acesso em: 4 Junho. 2018. 